require less make-up and are, therefore, easier to deal with than white people. In order to align and set up the cameras, these were presented with a set of Munsell colour chips illuminated by the normal studio lighting and the images on the picture monitors in the control room were compared with a similar set of Munsell chips illuminated with illuminant $C$, which has the chromaticity of the 'white' standard for the National Television System Committee colour television. When a programme involves film inserts, great care has to be taken to ensure a colour match between similar scenes which may be viewed in succession from a colour-television camera and from a colour-film scanner, or telecine machine. Although the necessarily low contrast required for the colour transmission seemed to be quite satisfactory for the compatible monochrome viewer there was, at times, a subtle change of mood in that the dark colours which were required for the colour viewer made the compatible black-and-white picture rather sombre. During the lecture, some very fine colour slides were projected, showing studio scenes for colour programmes.

Messrs. A. R. Stanley and S. N. Watson introduced "Colour Television Engineering: Equipment Problems and Techniques". The authors discussed five characteristics of colour television which gave least satisfaction to viewers during the B.B.C. colour fieldtrials mentioned in the historical survey of the previous paper. It had been clearly demonstrated that the colour cameras were the weakest link in the chain. The paper dealt with a number of matters which affect the correct reproduction of colour scenes. For example, no effort is made to ersure negative lobes in the spectral response characteristics of the colour analysis filters in the cameras, although it is possible to achieve an approximation to negativelobed characteristics despite the impossibility of using 'negative light'. The 'taking gamma' of the cameras is important, as are the errors due to shading (or spurious) signals in the image orthicon tubes used in the eameras. The latter may cause errors of hue, particularly in low-luminance patches of the scene. Since the phase of the modulated colour subcarrier determines the reproduced hue, any departure from linearity of the phase/frequency characteristic of any part of a transmission network in the region elose to the frequency of the subcarrier $(2.66 \mathrm{Mc} / \mathrm{s}$. in the case of the National Television System Com. mittee system adapted to 405 -line standards) causes errors of hue. In particular, if the transmission system suffers from a non-linear effect which causes a change of phase to occur in sympathy with a change of signal-level (in the composite video signal the luminance signal and the chrominance or modulated subcarrier signal are added) a change of hue and brightness will result. The possible existence of this phenomenon places a rather stringent requirement on the linearity of television equipment such as studio broadeast apparatus, and radio links. An excellent demonstration followed the lecture. Colour film and slides originating in a B.B.C. studio were transmitted by Post Office equipment to the lecture theatre of the Institution of Electrical Engineers and the received images were projected on to the large screen by a Marconi's Wireless Telegraph Co.'s three-tube Schmidt projector. The registration of the three primary-colour images was very good indeed. The effect on hue of a $10^{\circ}$ change of subcarrier phase was shown and also the deterioration in picture quality to be expected from the use of two transmission links in series. Both deteriorations were slight. The technique of using a low-pass filter to attenuate all Fourier components (and noise) of the luminance signal, which would otherwise occupy the frequency band set aside for the chrominance signal (which shares an upper part of the full luminance channel) and the subsequent employment of a non-linear device ('crispener') to reconstitute artificially an impression of sharpness was also successfully demonstrated. An electronic masking unit showed how an improvement can be made to the properties of colour film for colour-television purposes.

R. D. A. Maurice

\title{
STUDY OF DEFECTS IN PORPHYRIN METABOLISM BY MEANS OF ISOTOPES
}

\begin{abstract}
$\mathrm{T}$ HE Biology Division of the French Atomic Energy Commission held, during September 1960 , a colloquium at Saclay on the use of tracers in the study of diseases of porphyrin metabolism. Participants from Europe and the United States enjoyed three days of intense discussion as guests of the Atomic Energy Commission and the Ministry of National Education. The topics debated ranged over a wide field; full proceedings of the conference will be published in due course.

In the opening address, Prof. A. Bénard reviewed our present knowledge of porphyrin biosynthesis and of the disturbances giving rise to the different clinical forms of porphyria. It was his view that such diseases were variants of a single fundamental abnormality. Symptoms were due not to the porphyrins themselves but to associated metabolic disturbances such as interference with the synthesis of purines. $\mathrm{He}$ concluded an impressive survey by reference to recent therapeutic measures which have shown some promise in the treatment of acute
\end{abstract}

porphyria, namely, administration of $2: 3$-dimercapto-propanol, ethylenediaminetetraacetic acid or adenosine monophosphate.

The genetic aspect of the porphyrias was then dealt with. It was pointed out that the several hundred South African cases of 'porphyria variegata', all being descended from a single pair of Dutch settlers, necessarily represent manifestations of the same genetic abnormality or group of abnormalities found in the progenitors and might well, therefore, display a characteristic pattern. A fascinating account of the recently discovered 'Turkish porphyria' was given by Dr. R. Schmid. It is an acquired porphyria due to consumption of wheat containing hexachlorobenzene. Several thousand human cases have occurred and the disease has also been reproduced experimentally in animals. Topies further discussed during the first day's sessions were the symptomatology of acute intermittent porphyria and its causation, and also the difficulties attending the interpretation of investigations made with isotopic tracers on such patients. 
While it is generally felt that the excessive excretion of porphobilinogen and $\delta$-aminolævulic acid in acute hepatic porphyria is due to over-production of these materials, the exact biochemical mechanism leading to such over-stimulation of the porphyrin pathway is still in doubt. Experiments designed to test the possibility of restricted conversion of glycine into serine were inconclusive. A hint as to the means by which $\delta$-aminolævulic acid production is normally regulated may be forthcoming from the experiments described by Shemin who showed, in one system studied, that $\delta$-aminolævulic acid is itself an inhibitor of the enzyme producing it. This points to the possibility of a negative feed-back control operating in the normal cell. The combination of administration of porphyrinogenic drugs with pantothenate deficiency promises to throw further light on the development of the nervous symptoms in acute porphyria. It has been generally assumed, since the self-experiment of Meyer-Betz, that photosensitization in the cutaneous porphyrias is actually caused by the porphyrins themselves. Direct evidence was lacking, however, until quantitative measurements were made by Magnus and collaborators on patients with the use of a powerful monochrometor. This technique and the results it afforded were described and exemplified by the case of a man with sun-burn type photosensitivity who, nevertheless, showed highest cutaneous sensitivity in the Soret band region of the spectrum. Further investigation showed that his red cells and freces did, in fact, contain abnormally large quantities of porphyrins.

The increase in urinary excretion of porphyrin which accompanies lead intoxication has aroused the interest of biochemists for many years, but is as yet little understood. New light may be thrown on this problem by the finding of Gajdos and his collaborators that lead ions interfere with the passage of iron through the membrane of the developing red cell, the stroma, under these conditions, retaining iron rather firmly.

The biochemical mechanism of incorporation of iron into protoporphyrin and the part played by 'bound' forms of these reactants, the biosynthesis of porphyrins by human leucocytes and the metabolism of hæmoglobin within the red cell were next considered. It would appear from the work of Schapira and his co-workers that the hæmoglobin molecule within the erythrocyte is not metabolically inert, but that progressive structural alterations occur with the course of time. The effects of radiation on the synthesis of hrmoglobin in the bone marrow, and the results of a great deal of work on the relation of porphyrin structure to $\mathrm{X}$-ray sensitivity, were also reported.

At the close of the meeting, Prof. C. Rimington endeavoured to lay before participants an appraisal of the most significant conclusions and to point to the fields from which the next major advances towards an understanding of normal and pathological porphyrin metabolism might be expected to come. He took the opportunity of thanking the organizers and the two bodies sponsoring the colloquium for their excellent work on behalf of porphyrin biochemistry and for their generous hospitality. This meeting will be long remembered with gratitude and pleasure by those who were gathered together in the stimulat. ing atmosphere of Saclay.

\section{Rimington}

\section{CONSERVATION OF BRITISH NATIONAL PARKS}

\begin{abstract}
T its recent eleventh annual report the National 1 Parks Commission referred briefly to the question of afforestation in the National Parks, especially on Dartmoor and Exmoor, and also to its disappointment at the delay in amending the Act, particularly with regard to financial resources. Both these aspects have since been the subject of short adjournment debates in the House of Commons. In the first of these, on March 29, Mr. E. du Cann raised the question of afforestation, particularly in the Dartmoor and Exmoor National Parks. While supporting the voluntary agreement recently reached between the Timber Growers" Organization, the Country Landowners' Association, the Forestry Commission and the National Parks Commission regarding afforesta. tion in the National Parks, Mr. du Cann questioned whether a voluntary agreement would be sufficiently effective, as it did not include all those concerned with afforestation in such areas.
\end{abstract}

In his reply, the Parliamentary Secretary to the Ministry of Housing and Local Government, Sir Keith Joseph, agreed that it was important to give the new scheme a fair trial. He thought that there was no reason to fear that landowners in the areas concerned, who were not members of the Association, would not, as individuals, comply with such agresments and, in reply to a specific question about trees on High House Moor, Dartmoor, said that discussions were still proceeding between the proposed developers and the authorities. On this specific issue it should be noted that considerable uneasiness still exists that the National Parks Commission will not be supported. The parties to the agreement were not despondent as to the prospects that the agreement would succeed, and Sir Keith Joseph appeared to have substantial grounds for his confidence that the spirit of co-operation already demonstrated by the production of this voluntary agreement, and the way it had been received and implemented indiceted that, with common sense, it should be possible to reconcile the claims of forestry and the National Parks and the rights of landowners.

Nevertheless, Sir Keith recognized that failure of the scheme would create a new situation and this would have to be faced. Meanwhile, he said, the Minister wished to give the scheme a fair trial and he made it clear that he also wished that all concerned, whether members of the particular organiza. tions or not, should participate in this voluntary consultation at all times. The Minister and the National Parks Commission would keep progress under careful review.

On the wider issue raised in the debate on March 30 , progress also may be regarded as largely a matter of co-operation and common sense, but on the part of the Government common sense implies providing the financial means to the end enacted. The root of the difficulties encountered in the development of 